\title{
"Qualification of DC Brush Motors used in Spacecraft Missions using Logistic Regression Model - An Analytical Approach"
}

\author{
K. Shwetha, Dr.N.S. Narahari and Chandra Shekar Prasad
}

\begin{abstract}
DC brush motor undergoes rigorous performance testing to predict the failures occurring. Acceptance test levels are set with margin expected flight/operations levels and qualification test levels are set above the expected operation levels to check for the survivability of DC brush motor in space. Performance testing is important to design and integration in a planned test process in which DC brush motor were tested under actual or simulated mission profile environments to disclose design deficiencies and to provide information on failure modes and mechanisms. Statistical models are helpful in this process. The Logistic Regression Model is the commonly used parametric statistical models and is one of the statistical techniques that are used for analyzing and predicting performance with binary outputs. The objective was to develop Logistic Regression Model and is designed to examine the categorization of dependent variables in the quantitative analysis for the performance of DC brush motor. The work carried out demonstrates the development of the Logistic Regression Model for performance prediction of the DC brush motors for deploying unfurlable antenna. The methodology includes performance test data and transforming the dependent variables into binary digits. And to estimate the probability of success of DC brush motor. The model developed is useful in the GO-NO-GO decision making with regard to the DC brush motors which is one of the critical components in the space module. This paper adds value to the decision making process through statistical validation using Logistic Regression Model. This Model helps the decision makers in qualifying the components based on performance tests. The Model developed shows the working condition of motor can said to be good since the model fit is good. The reliability performance of the DC brush motor in the working condition is significantly good.
\end{abstract}

Keywords--- Acceptance Test, DC Brush Motors, Logistic Regression, Qualification Test, Spacecraft

K. Shwetha, Assistant Professor, Department of Mechanical, Engineering, $R V$ College of Engineering, Mysore Road, Bangalore-59. Karnataka, India. E-mail:shwetha.krishna646@gmail

Dr.N.S. Narahari, Professor \& Dean, Placement and Training, Department of Industrial Engineering, $R V$ College of Engineering, Mysore Road, Bangalore-59.Karnataka, India. E-mail:naraharins@rvce.edu.in

Chandra Shekar Prasad, Scientist / Engineer - SE, System Reliability Group, ISRO-ISAC, RAMD, Bangalore -17.Karnataka, India. Email:csprasad@isac.gov.in

\section{INTRODUCTION}

SPACECRAFT components must withstand the launch loads and the environmental conditions that are encountered in the space for successful mission of the spacecraft. These components are tested rigorously and performance data analyzed for evaluating them for Acceptance decision. DC brush motors must withstand vibration and extreme temperatures during launch and on orbit. The motor is rigorously tested under simulated environmental conditions for performance as part of the acceptance test procedures. Acceptance tests include vibration tests and thermo vacuum cycling. Speed in rpm is calculated for different settings of voltage, load (torque) and temperature during performance tests. Current is also monitored during the test. Four motor units undergo the acceptance level tests. A motor unit assembled to fixture is used for vibration test, followed by thermo vacuum test.

Objective of these tests are to check the performance of the motors for launch loads and simulated environments. The test set up consists of a fixture on which the motor is mounted, a provision to apply the required torque, a DC Power Source, a Electronic driver package and a stop watch to time the period of the test. Motor Speed is estimated by counting number of rotations for a given time. The main Objective of this paper is to develop a Logistic Regression Model to predict the performance of DC brush motors based on test result for space applications. This model is useful in the GO-NO-GO decision making with regard to the suitability of the DC brush motors which is a critical component in the deployment mechanism, for activating the unfurlable antenna of the spacecraft. The performance data has been effectively utilized in the development of a Logistic Regression Model which can be deployed to assist the decision makers in deciding on the Acceptance of the motors based on performance characterization of the DC brush motors. 


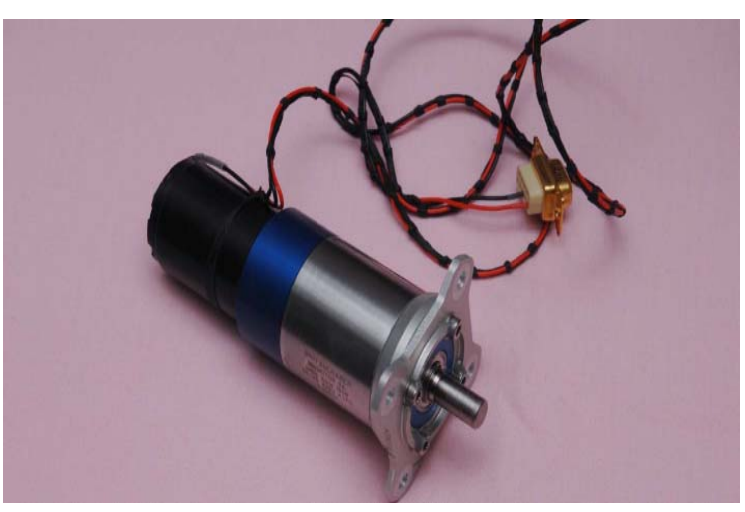

Figure 1: DC Brush Motor

\section{LiteratURE REVIEW}

The literature survey reveals the application and implementation of Logistic Regression for the various set of data used for several application. A few of the relevant literature has been briefly reviewed.

Dalton S. Rosario presented highly effective Logistic Regression Model for signal detection using maximum likelihood method and asymptotic behaviour. This analysis is mainly based on the signal data collection and Logistic Regression Model framework [1]. Ruibin Xi, Nan Lin, and Yixin Chen presented Compression and Aggregation for Logistic Regression Analysis in Data Cubes. A novel scheme to compress the data in such a way that the reconstruct Logistic Regressions models are done to ensure that first-order approximation to the maximum likelihood estimating are met [2]. F. Zhou, D. Wu, X. Yang, and J. (Roger) Jiaop presented Ordinal Logistic Regression for the affective Product Design. The Logistic Regression Model in this work is used to deal with affective product design, mapping from the designer domain to the customer domain [3]. Leif E. Peterson presented Maximum Likelihood Logistic Regression using Metaheuristics. The Maximum likelihood-based Logistic Regression coefficients and fitness growth rates for several Metaheuristics techniques were compared with results from Newton-Raphson iteration [4]. Alyson G. Wilson, Todd L. Graves, Michael S. Hamada and C. Shane Reese presented advances in data combination, Analysis and collection for System Reliability Assessment. The combination of multiple sources of information to assess the reliability of a single component using genetic algorithm, lifetime data, Logistic Regression, Markov chain Monte Carlo, Metropolis algorithm, and multilevel data are attempted [5]. J. Umakant, K. Sudhakar, P.M.Mujumdar and C. Raghavendra Rao presented Customized Regression Model for Improving Low Fidelity Analysis Tool. The Regression technique is customized to discover a functional form between the Low Fidelity Analysis response and High Fidelity Analysis response and develop an uncertainty model that estimates the high fidelity function with greater confidence in the regions of interest to the designer [6].Richard DeLoach and Iwan Philipsen presented Stepwise Regression Analysis of MDOE Balance Calibration Data Acquired at DNW. A comparison of two experiment design methods applied in the calibration of a strain-gage balance is made. One features a 734-point test matrix in which loads are varied systematically according to a method commonly applied in aerospace research and known in the experiment design as One Factor at a Time (OFAT) testing [7]. N. Ulbrichand T. Volden presented Regression Analysis of Experimental Data using an Improved Math Model Search Algorithm. The improved math model search algorithm was used for the linear regression analysis of experimental data. The algorithm uses forward selection in order to build a math model for the regression analysis [8].N. Ulbrich presented Regression Model Optimization for the analysis of experimental data. A math model search algorithm was developed to determine a recommended math model for the multivariate regression analysis of experimental data. The search algorithm is applicable to classical regression analysis problems as well as wind tunnel strain-gage balance calibration analysis applications [9].

\section{DC BRUSH MOTORS}

\subsection{Development of the Logistic Regression Model for Qualification of DC Brush motors}

Logistic Regression is a powerful statistical analysis used extensively in the that are commonly used in analysing binary data, that arise in studying relationships between the motor working and motor not working status. Logistic Regression is a statistical technique for examining relationships between an outcome measure on a nominal scale and one or more other variables often called covariates. The variables can be used on any type of scale. The outcome measure is called a dependent variable and the covariates are called independent variables or repressors. Logistic Regression can be analysed by using package named SYSTAT software.

\subsection{Analysis of Performance Test Data of DC Brush Motor using Logistic Regression Model}

The model development involves the following steps as part of the methodology

\subsubsection{Selection of the Dependent and Independent Variables}

The selection of variable is made for the Logistic Regression based on the parameter which is influencing the working of motor. Speed is important deciding parameter for the deployment of antenna for spacecraft.

Variables:

Dependent variable: Speed. (The speed of motor which influences the deployment mechanism of antenna)

Independent variable: Torque, current, voltage, temperature, direction of rotation. (These are controllable variables for the satellite mission)

\subsubsection{Transforming the Dependent Variable}

To develop the Logistic Regression Model, the actual data values of the dependent variables are transformed from metric to binary digits as either 0 or 1 . In this model the dependent variable is transformed into binary digits as 0 or 1 based on the speed of the motor. The stall condition is assigned as 0 , in which the motor has stopped working. And unstalled condition is assigned as 1 . Thus the binary status is decided on the condition of working of the DC brush motors. 


\subsection{Estimating the Logistic Regression Model using Maximum Likelihood}

In this Logistic Regression Model, the maximum likelihood estimates the values which produce the largest value for the likelihood equation. In Logistic Regression the likelihood value measures of parameters fit the model of the data. The model is estimated after several iterations from the significance and likelihood value. The log likelihood statistic is the difference between the two model fits, is $2 *[\mathrm{LL}(\mathrm{N})-\mathrm{LL}$ (0)] is obtained as 50.843 for Acceptance test and 0.711 for Qualification test. Since, the value obtained is large it can be concluded that the model fit is fairly good. This indicates that the parameters studied are usable to provide adequate information to predict the acceptability of the DC brush motors.

\subsubsection{Logistic Regression Model of the Acceptance Test}

The performance test data was analysed using SYSTAT software using the structure of a Logistic Regression Model. The output obtained is summarized in Table 1 and 2.

Table 1: Binary Logit of Acceptance Test

\begin{tabular}{|c|c|c|c|c|}
\hline Parameter & Estimate & $\begin{array}{c}\text { Standard } \\
\text { error }\end{array}$ & t-ratio & p-value \\
\hline Constant & 13.713 & 5.825 & 2.354 & 0.019 \\
\hline Torque & -1.653 & 0.662 & -2.497 & 0.013 \\
\hline Current & -0.057 & 0.036 & -1.589 & 0.112 \\
\hline Torque:current & 0.012 & 0.006 & 1.854 & 0.064 \\
\hline
\end{tabular}

Table 2: Probability Analysis for the Performance Test Data of

\begin{tabular}{|c|c|c|c|c|}
\multicolumn{5}{c}{ Acceptance Test } \\
\hline Parameter & $\begin{array}{c}\text { Odd- } \\
\text { ratio }\end{array}$ & $\begin{array}{c}\text { Upper } \\
\text { Limit }\end{array}$ & $\begin{array}{c}\text { Lower } \\
\text { Limit }\end{array}$ & probability \\
\hline Torque & 0.191 & 0.701 & 0.052 & 0.160 \\
\hline Current & 0.945 & 1.013 & 0.880 & 0.485 \\
\hline $\begin{array}{c}\text { Torque: } \\
\text { current }\end{array}$ & 1.012 & 1.024 & 0.999 & 0.502 \\
\hline
\end{tabular}

\subsubsection{The Software Results are}

\subsubsection{The Goodness of Fit Measures as Follows}

The measures of likelihood, Mc. Fadden values have been obtained from the Binary Logit analysis.

Log Likelihood of constants model $=\mathrm{LL}(0)=-41.756$

$2 *[\mathrm{LL}(\mathrm{N})-\mathrm{LL}(0)]=50.546$ with 3 degree of Chi-square

p-value $=0.000$ 0.605

McFadden's Rho-Squared $=[\operatorname{LL}(\mathrm{N})-\mathrm{LL}(0)] / \mathrm{LL}(0)=$ LL(N) - Log likelihood of full model, LL(0) - Log likelihood of constant model. For McFadden's Rho-Squared is always positive value, since modulus value is considered.

\subsubsection{Logistic Regression Model of the Qualification Test}

The performance test data was analyses using SYSTAT software using the structure of a Logistic Regression Model. The output obtained is summarized in Table 3 and 4 for the Qualification test.
Table 3: Binary Logit of Qualification Test

\begin{tabular}{|c|c|c|c|c|}
\hline Parameter & Estimate & $\begin{array}{c}\text { Standard } \\
\text { error }\end{array}$ & t-ratio & p-value \\
\hline Constant & -1.946 & 1.069 & -1.820 & 0.069 \\
\hline voltage & 0.343 & 0.073 & 4.672 & 0.000 \\
\hline
\end{tabular}

Table 4: Probability Analysis for the Performance Test Data of Qualification Test

\begin{tabular}{|c|c|c|c|c|}
\hline \multicolumn{5}{|c|}{$95.0 \%$ bounds for the parameters } \\
\hline Parameter & $\begin{array}{c}\text { Odd- } \\
\text { ratio }\end{array}$ & $\begin{array}{c}\text { Upper } \\
\text { Limit }\end{array}$ & $\begin{array}{c}\text { Lower } \\
\text { Limit }\end{array}$ & probability \\
\hline voltage & 1.409 & 1.626 & 1.220 & 0.58 \\
\hline
\end{tabular}

\subsubsection{The goodness of Fit Measures as Follows}

Log Likelihood of constants only model $=\operatorname{LL}(0)=-30.897$ $2 *[\operatorname{LL}(\mathrm{N})-\mathrm{LL}(0)]=43.947$ with 1 degree of Chi-square pvalue $=0.000$ 0.711

McFadden's Rho-Squared $==[\operatorname{LL}(\mathrm{N})-\mathrm{LL}(0)] / \operatorname{LL}(0)=$

\subsection{Assessing the Goodness of Fit of the Estimated Model}

This step deals with the assessment of the model fit based on the performance data as an output to the model

\subsubsection{Goodness of Fit Measure Obtained are}

\section{i. $\quad$ Acceptance Test}

Likelihood ratio $=2 *[\mathrm{LL}(\mathrm{N})-\mathrm{LL}(0)]=50.546$ with 3 degree of freedom Chi-square $\mathrm{p}$-value $=0.000$ Upper bound $=\mathrm{LL}(\mathrm{O})=-41.756$

Mc. Fadden's $=0.605$

\section{ii. Qualification Test}

Likelihood ratio $=2 *[\mathrm{LL}(\mathrm{N})-\mathrm{LL}(0)]=43.947$ with 1 degree of freedom Chi-square p-value $=0.000$ Upper bound $=$ LL $(\mathrm{O})=-30.897$

Mc. Fadden's $=0.711$

LL(N) - Log likelihood of full model, LL(0) - Log likelihood of constant model

McFadden's pseudo $\mathrm{R}^{2}$ is used to measures the overall model fit. In the case of the DC brush motor pseudo $\mathrm{R}^{2}$ obtained is 0.609 for acceptance test and 0.711 for qualification test, which shows that that the model fit is fairly good.

The $\beta$ coefficients, standard errors and $\mathrm{p}$ values were estimated. Also the odds ratio and 95\% confidence intervals for each of the coefficients were estimated in the study of Logistic Regression. The odds of an event occurring was the ratio of the probability that will occur to the probability that it will not occur. In other words Probability (event) $\div$ Probability (no event). 


\subsection{Testing for Significance of the Coefficients}

The Logistic coefficient was statically significant, since the $p$-value obtained was closer to 0 , the model is significant. Using the odds ratio approach set 0 at the lower limit and infinity at the upper limit. The odd ratio shows the probability of success rates. Torque, current and voltage were significant and the interaction between torque and current was found to be significant. In this case probability of success was higher. Hence, the chances that motor working condition was significantly high.

\section{RESULTS}

The following significant result is obtained from the analysis using the Logistic Regression Model:

1. The working condition of motor can said to be good since the model fit is good, where McFadden's RhoSquared $=0.605$ for Acceptance test and 0.711 for Qualification test. The reliability performance of the DC brush motor in the working condition is significantly good.

2. The larger the maximum likelihood estimates value estimate model fit can be concluded to be fairly good. The value obtained from the analysis of DC brush motor of 50.546 with 3 degree of freedom and Chisquare $\mathrm{p}$-value $=0.000$ for acceptance test and 43.947 with 1 degree of Chi-square $p$-value $=0.000$ for Qualification test, shows the good fit of model.

3. Independent variables torque and current are significant and the interaction between torque and current is found to be significant in acceptance test and only voltage was found to be significant in Qualification test.

4. The torque and speed are the dependent variables, torque is proportional to the current. The deployment of antenna depends on the speed of the motor for the successful mission of spacecraft. The torque, current and voltage significantly influences the speed of the motor.

5. The current is approximately $240 \mathrm{~mA}$ and the torque loaded upto $10 \mathrm{~N} / \mathrm{m}$ are the specifications performed on $\mathrm{DC}$ brush motor. The torque, current and voltage variables met these specifications to perform on-orbit conditions.

\section{CONCLUSION}

Logistic Regression is used as a tool, which is used to predict the motor working condition in spacecraft by analyzing dichotomous outcome variables. A Logistic Regression Model for speed performance prediction of DC brush motors for spacecraft applications has been developed. This model will enhance the capability of the prediction of the performance of spacecraft components. Through the interpretation of the Logistic Regression output can be inferred that the odds ratio the probability of success is higher and $95 \%$ confidence intervals for each of the coefficients are estimated to study the influence of the dependent variable i.e. speed. The log likelihood statistic is the difference between the two model fits, is $2 *[\mathrm{LL}(\mathrm{N})-\mathrm{LL}(0)]$ is 50.843 for
Acceptance test and 43.947 for Qualification test. The value obtained is large, the model fit to the performance test data is fairly good. It can be concluded that the Logistic Regression Model is an useful technique for performance prediction of spacecraft components and can be used in arriving at the decisions, regarding acceptability or otherwise of the space component (in this case of DC brush motors) for conditions of space based on the ground level performance tests conducted under simulated conditions. The torque and current parameters meet the on-orbit conditions for the performance of DC brush motor with the starting torque and controllability led the systems acquiring accurate control of speed and position. In a brush DC Motor, torque control is accomplished easily. Output torque is proportional to current. Therefore, if the current is limited, the torque can also be limited which the brush motor achieve.

\section{ACKNOWLEDGEMENT}

The authors express sincere gratitude to Sri, Kamesh D, "Division Head", Sujith Kumar N, Scientist/Engineer, SRG at ISRO Satellite Centre for their valuable guidance, encouragement and support. The authors are also thankful to Dr.B.S..Satyanarayana, Principal RVCE, \& Dr. H.N. Narasimha Murthy, Dean PG Studies, Mechanical Engineering Department, R.V. College of Engineering for their valuable guidance.

\section{REFERENCES}

[1] Dalton S. Rosario, Highly Effective Logistic Regression Model For Signal (Anomaly) Detection, IEEE, Pp 817-820, ICASSC 2004.

[2] Ruibin Xi, Nan Lin, and Yixin Chen, Compression and Aggregation for Logistic Regression Analysis in Data Cubes, IEEE transactions on knowledge and data engineering, Vol. 21, No. 4, Pp 479-492, April 2009.

[3] F. Zhou1, D. Wu, X. Yang1, and J. Roger Jiao, Ordinal Logistic Regression for Affective Product Design, IEEE IEEM, Pp 1986-1990, Proceedings of the 2008 .

[4] Leif E. Peterson, Maximum Likelihood Logistic Regression Using Metaheuristics, International Conference on Machine Learning and Applications, Pp 509-514, 2009.

[5] Alyson G. Wilson, Todd L. Graves, Michael S. Hamada and C. Shane Reese, Advances in Data Combination, Analysis and Collection for System Reliability Assessment, Institute of Mathematical Statistics in Statistical Science, Vol. 21, No. 4, Pp 514-531, 2006.

[6] J. Umakant, K. Sudhakar, P.M. Mujumdar and C. Raghavendra Rao, Customized Regression Model for Improving Low Fidelity Analysis Tool, 11th AIAA/ISSMO Multidisciplinary Analysis and Optimization Conference, Portsmouth, Virginia. AIAA 2006-7118, Pp 1-13, 6-8 September 2006.

[7] Richard DeLoach, and Iwan Philipsen, Stepwise Regression Analysis of MDOE Balance Calibration Data Acquired at DNW, 45th AIAA Aerospace Sciences Meeting and Exhibit, Reno, Nevada, AIAA 2007144, Pp 1-25, 8-11 January 2007.

[8] N. Ulbrichand T. Volden, Regression Analysis of Experimental Data Using an Improved Math Model Search Algorithm, 46th AIAA Aerospace Sciences Meeting and Exhibit, Reno, Nevada, AIAA 2008833, Pp 1-21, 7 - 10 January 2008.

[9] N. Ulbrich, Regression Model Optimization for the Analysis of Experimental Data, 47th AIAA Aerospace Sciences Meeting Including The New Horizons Forum and Aerospace Exposition, Orlando, Florida, AIAA 2009-1344, Pp 1-31, 5 - 8 January 2009. 


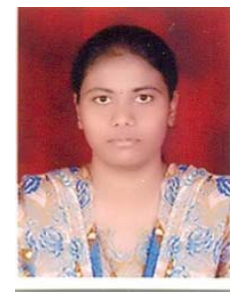

K. Shwetha, was born in 1988 Bangalore, She is a Bachelor of Engineering in Industrial Engineering from Dr. Ambedkar Institute of Technology, Bangalore. Afflicted to VTU and obtained his Master degree in Product Design and Manufacturing from R.V.College of Engineering, Bangalore. Afflicted to VTU. She was Research Scholar in Indian Satellite Research Organization (ISAC) for 1 year, 2011-2012. Currently Working as Assistant Professor in Department of mechanical Engineering in R.V.College of Engineering.

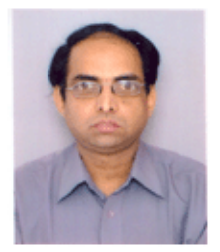

Dr.N.S. Narahari was born in the village of pollachi in the state of tamilnadu on $23^{\text {rd }}$ December, 1961 . He is a Bachelor of Engineering in Industrial Engineering from Bangalore University and obtained his Master degree in Reliability Engineering from Indian Institute of Technology, Mumbai. $\mathrm{He}$ has been awarded the Doctorate degree by the Avinashilingam Deemed University in the Faculty of Engineering for his research on the topic "Application of Decision Support System for Human Resource Management Problems Using System Dynamics Approach". He has got over 25 years of teaching experience. His research interests are in the fields of Quality Engineering, Reliability Engineering and Industrial Engineering. He has several publications in the National \& International Conferences \& Refereed International Journals. He has guided more than 80 Projects at the Undergraduate \& Post Graduate Engineering \& MBA Programs. He is an academic Counselor in the Management Programme of the Indira Gandhi National Open University (IGNOU). He has featured in the IGNOU Gyana Vani Radio \& TV Channels. He has Professional Membership in the Indian Society of Technical Education (ISTE), The Indian Institution of Industrial Engineering (IIIE), Quality Circle Forum of India (QCFI) and very recently the IEEE -USA. He has served on the Board of Several University academic bodies. He has been Invite to Judge the Quality Circle Competition in several industry fora.He is in the Academic Council of the Nettur Technical Training Foundation (NTTF). He is currently the Chief Project Leader of the Entrepreneurship Development Cell of the RV College of Engineering Bangalore. He has Successfully Executed Funded Research Projects under the AICTE- MODROBS Scheme and the AICTE-TAPTECH Scheme. He has organized \& conducted many Technical Seminars, Conferences, Symposia and workshops in the relevant areas of his specialization at National Level. He has handled key assignments at the Institution \& University Levels. He has been invited to be the resource person in Several Technical Conferences and has contributed to the Course Delivery through the VTU EDUSAT Channel. $\mathrm{He}$ has received several distinctions and awards for his professional contributions to the field. He has been awarded Fellowship by the Indian Institution of Industrial Engineering and also been recognized with the Dr. S.R. Gollapudi award for his contribution to the field of Industrial Engineering. He has also been recently recognized with H.K Firodia Award a prestigious national award for contribution to the field of industrial engineering.

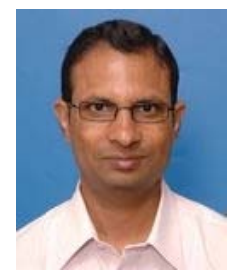

Chandra Shekhar Prasad was born in Siwan, India on $05^{\text {th }}$ May 1973. Mr. Prasad received his B.S. in Mechanical engineering from Ranchi University, India in 1997 and M.E. in Mechanical engineering from Indian Institute of Science, Bangalore, India in 2004. $\mathrm{He}$ is working in ISRO Satellite Centre, Bangalore, India since 1997. He has over 15 years experience in spacecraft deployable mechanisms in project engineering management capacities. He has been involved in the testing, certification and analysis of space-based structures, deployable mechanisms and Unfurlable Antenna Deployment Mechanism. His most notable projects include the Chandrayaan-1 Dual Gimbal Antenna Mechanism, Solar Array Deployment mechanisms of LEO and GEO spacecrafts, UHF deployment mechanism and Unfurlable Antenna mechanism of GEO Spacecraft. Mr. Prasad is currently a member of Astronautical Society of India and primarily involved in Reliability assessment of spacecraft deployable mechanisms. He has authored numerous technical papers. His current research interests include reliability analysis of spacecraft deployable mechanisms and development of new techniques for analysis and testing of mechanical systems. 